\title{
Studies on the removal of dyes from water using carbon nitride/graphene oxide composites as adsorbents.
}

\section{Junia T. Martins*, Carlos H. Guimarães, Patricia Prediger.}

\begin{abstract}
Dyes in water are a currently environmental concern, such as basic blue 26, being indispensable to remove it from water. Graphene oxide and carbon nitride are potential filtering agents to pollutant removal. Therefore this study aimed optimizes the dye sorption process in water using carbon nitride and oxide graphene composites.
\end{abstract}

Key words:

Carbon nitride, Graphene oxide, dye removal.

\section{Introduction}

Carbon Nitride $(\mathrm{CN})$ is a versatile material, wich has porous surface and it is negatively charged in water ${ }^{1}$. The Graphene Oxide (GO) is a stable nanomaterial with high superficial area, wich has been applied to surfactants ${ }^{2}$ and dye removal ${ }^{3}$.
Fig 1. a) CN

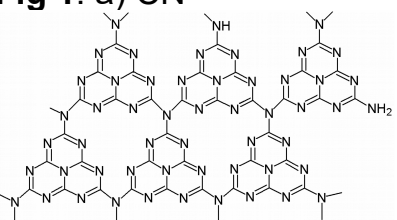

b) $\mathrm{GO}$

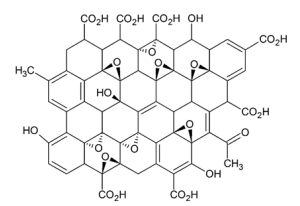

Considering the great sorbent capacity of both materials, this study aimed to study dyes removal from water using composites based on CN/GO as adsorbents.

\section{Results and Discussion}

The GO/CN composites (30/70, 50/50 and 70/30) were obtained by dispersing the materials in water, under stirring and sonication. It was evaluated the removal of three different basic dyes: Green 4 (BG4), Brown 4 (BB4) and Blue 26 (BB26) and two types of $\mathrm{CN}$ adsorbent (called RCN and RHS). Carbon nitride $\mathrm{CN}$ e RHS have pore volume of 0.88 and $0.48 \mathrm{~cm}^{3} / \mathrm{g}$ and surface area of 200.3 and $164.5 \mathrm{~m}^{2} / \mathrm{g}$, respectively.

The highest removal efficiency occurred in the tests with BB26 dye. Concerning the two $\mathrm{CN}$, the most porous material (RCN) was the best BB26 adsorbent. In addition, BB26 adsorption experiments were carried out with different materials: pure $\mathrm{GO}$ and $\mathrm{CN}$ and the $\mathrm{GO} / \mathrm{CN}$ composites (Figure 1). The best BB26 adsorbent was the composite GO/CN 50/50, which reached a removal capacity of $390 \mathrm{mg} / \mathrm{g}$. Due to the best results, the composite $\mathrm{GO} / \mathrm{CN} 50 / 50$ was chosen to the optimization process.

Figure1. BB26 removal tests with $\mathrm{GO}, \mathrm{CN}$ and the different composites.

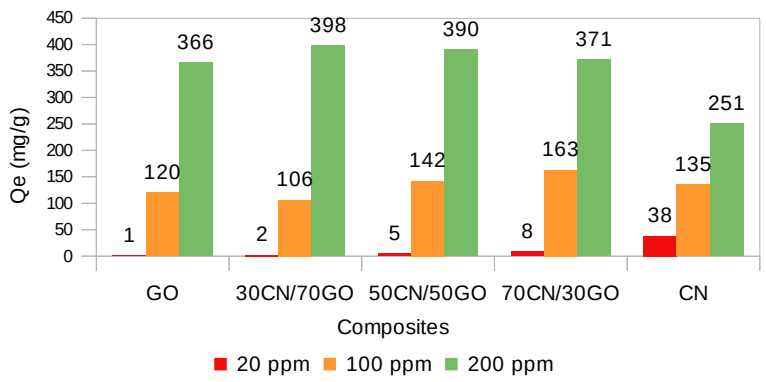

The optimization process was performed varying several parameters as time, $\mathrm{pH}$, temperature, adsorbent loading, BB26 concentration and sonication. In relation to the time of adsorption, the obtained data are presented in the Figure 2. It is noted that the equilibrium was achieved after $60 \mathrm{~min}$, indicating the fast dye adsorption onto GO/CN composite.

Figure 2. Variation of the adsorption time in the BB26 removal by $\mathrm{GO} / \mathrm{CN}(50 / 50)$ composite.

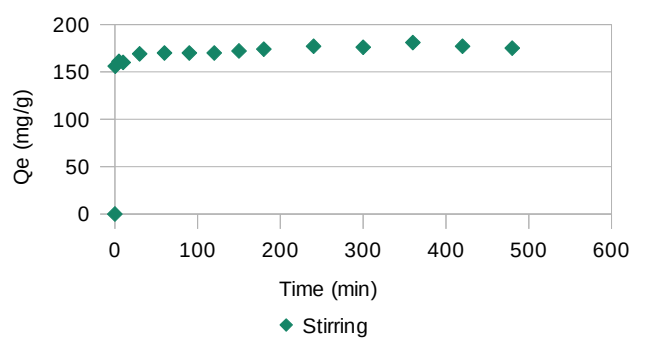

Regarding composite loading, the composite was used in different concentration between 0.05-0.4 g/L (Figure 3). The obtained results indicated the high removal capacity of $\sim 700 \mathrm{mg} / \mathrm{g}$ and removal of $99 \%$ at $0.3 \mathrm{~g} / \mathrm{L}$.

Figure 3. BB26 removal test varying composite loading $50 \mathrm{CN} / 50 \mathrm{GO}$

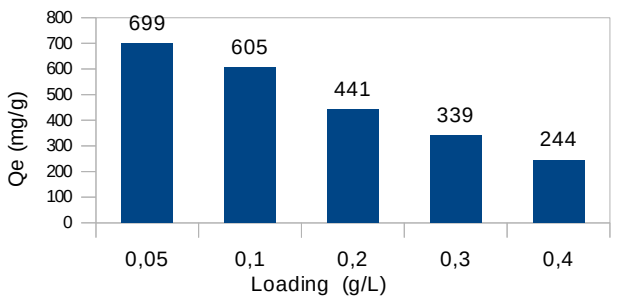

\section{Conclusions}

We conclude that the optimized scenario to run the BB26 dye removal is using the GO/CN (50/50) composite is the time of 60 minutes, adsorbent load of $0.1 \mathrm{~g} / \mathrm{L}$, BB26 concentration of $100 \mathrm{mg} / \mathrm{L}$ and sonication for $2 \mathrm{~min}$. Additional experiments are in progress in our lab.

\footnotetext{
${ }^{1}$ Miller, T. S.; Belen Jorge, A.; Suter, T. M. e Sella. A.; Corá. F and McMillan, P. F. Phis. Chem.Chem.Phys., 2017, 19, 15613.

${ }^{2}$ Prediger P.; Cheminski, T.; Neves, T. F.; Nunes, W. B.; Sabino, L.; Picone, C. S.F.; Oliveira and R. L, Correia, C. R. D. J. Environ. Chem. Eng., 2018, 6, 1. ${ }^{3}$ Alwan, S. H.; Alshamsi, H. A. H.; Jasim J, L. S., J. Mol. Struct., 2018, 1161, 356.1 .
} 